\title{
Blended and e-learning in pediatric education: harnessing lessons learned from the COVID-19 pandemic
}

\author{
Dominic A. Fitzgerald ${ }^{1,2}$ (D) $\cdot$ Karen M. Scott ${ }^{2} \cdot$ Michael S. Ryan ${ }^{3}$ \\ Received: 22 April 2021 / Revised: 3 June 2021 / Accepted: 7 June 2021 / Published online: 29 July 2021 \\ (C) Crown 2021
}

\begin{abstract}
Face-to-face education as the traditional basis for medical education was disrupted by the COVID-19 pandemic as learners and educators were moved online with little time for preparation. Fortunately, as online learning has grown, together with medical education shifting to problem-based and team-centered learning over the last three decades, existing resources have been adapted and improved upon to meet the challenges. Effective blended learning has resulted in innovative synchronous and asynchronous learning platforms. Clearly, to do this well requires time, effort, and adjustment from clinicians, educators, and learners, but it should result in an engaging change in teaching practice. Its success will rely on an evaluation of learning outcomes, educator and learner satisfaction, and long-term retention of knowledge. It will be important to maintain ongoing assessment of all aspects of the medical education process, including how to best teach and assess theory, physiology, pathology, history-taking, physical examination, and clinical management.

Conclusion: The COVID-19 pandemic triggered emergency transitional processes for teaching and assessment in medical education which built upon existing innovations in teaching medicine with the use of technology. These strategies will continue to evolve so as to provide the basis for an enduring hybrid teaching model involving blended and e-learning in medical education.

\section{What is Known:}

- Most pediatricians provide clinical teaching to medical students and residents, but few have had formal training in online educational approaches and techniques.

- Being able to adapt to new and innovative integrated teaching methods is of key importance when becoming a competent teacher.

What is New:

- This review presents an up-to-date summary of best practice in blended and e-learning and how it may be optimally delivered.

- Knowledge of the principles of e-learning, and how people learn more generally, helps pediatricians shape their clinical teaching and facilitates better interaction with medical students and residents.
\end{abstract}

Keywords Clinical teaching; Active learning; Blended pediatric education; Blended learning; Online learning

Communicated by Peter de Winter

Series Editor: Paul Brand

This article is part of the Topical Collection on The Art and Science of Clinical Pediatric Education

Dominic A. Fitzgerald

dominic.fitzgerald@health.nsw.gov.au

Karen M. Scott

karen.scott@health.nsw.gov.au

Michael S. Ryan

michael.ryan1@vcuhealth.org
1 Department of Respiratory Medicine, The Children's Hospital at Westmead, Locked Bag 4001, Westmead, Sydney, New South Wales 2145, Australia

2 Discipline of Child and Adolescent Health, The Children's Hospital at Westmead Clinical School, Faculty of Health Sciences, University of Sydney, Westmead, Sydney, New South Wales 2145, Australia

3 Children's Hospital of Richmond at Virginia Commonwealth University, Richmond, VA 23298, USA 


\section{Introduction}

The COVID-19 pandemic led to profound disruptions across the globe. In addition to the healthcare impact, physicians and physicians-in-training were confronted with a secondary challenge: the conversion of learning from face-to-face to virtual, remote instruction. Initial hesitancy around this method included concerns around technical support for staff and students; up-front costs for making the transition to more asynchronous, remote learning; and reluctance for change from busy educators [1]. However, the medical education community rallied around the need to preserve teaching and developed emergency remote teaching to meet the prevailing needs to maintain medical education and assessment [2]. While this mode of learning was necessary to deal with the immediate needs caused by the pandemic, it is likely that many of the innovations are here to stay. The online teaching model continues to evolve and will likely form an integral part of a hybrid teaching model with synchronous and asynchronous learning opportunities. In this manuscript, we describe the conversion to online learning platforms, the evidence around such learning methods, and the future of blended and e-learning. To highlight the potential for an adaptive strategy with online learning, a practical example of a short clinical scenario is presented [Text Box 1].

Text Box 1

Short clinical teaching scenario

You have been asked to host a 1-h teaching session for a group of 12 medical students using the Zoom platform. This is a new opportunity for you as you have been asked to translate your clinical experience and face-to-face small group teaching experience of common clinical presentations in the emergency department into online learning for your medical students who are new to pediatrics. Previously, you are used to groups of 6-8 students and have run sessions successfully by asking a lot of questions, stimulating interaction and debate using a whiteboard in a tutorial room. The students have been given this short stem for the tutorial:

A previously well 15-month-old boy is brought into the emergency department because of inspiratory stridor and breathing difficulty by his parent. Your tasks are to be able to:

1. Describe to the tutor how you would distinguish between the symptoms of upper airway obstruction and lower airway problems in a young child who cannot explain their symptoms to you

2. Working in groups of 2-3, design a one-page parent information sheet on the symptoms and signs of breathing difficulty due to upper airway obstruction which you will use to present to the tutor (playing the role of the parent) using terms appropriate for a lay person to understand

3. Working in groups of 2-3, develop an evidence-based management plan for the treatment of croup based upon levels of severity [mild, moderate, and severe] which will be presented by one of your group using a maximum of 3 PowerPoint slides in 3 min.
Text Box 2

In the worked solution to croup scenario, it is envisaged that you will use traditional interactions of student-content, student-student, and student-teacher in providing opportunities for learning. The effective online learning principles are expanded upon further in Text Box 3 and the instructional design principles for multimedia in Text Box 4. More specifically, the preparation for this educational session will require some time to be invested, perhaps a couple of hours, to gather information on current best practice guidelines from national or international expert bodies [e.g., European Respiratory Society, British Thoracic Society], evidence for treatment strategies [e.g., "Up to Date"], teaching videos from university sites or international agencies [e.g., "You Tube"], as well as reading recent review articles [e.g., "Google Scholar" or "PubMed"]. A pre-reading list could be provided the week before the online teaching session.

1. Describe to the group how you would differentiate between the symptoms and signs of upper airway obstruction and lower airway problems.

a. Student-content and student-student derived. This provides an opportunity to be able to distinguish the differing diagnoses of stridor for viral croup or an inhaled foreign body versus viral-induced wheeze for medium and small airway obstruction.

b. It could be achieved with the use of student identified short audio and/or video clips of high pitched inspiratory stridor reflecting upper airway obstruction as opposed to the more musical sound of expiratory wheeze from the lower airways. Images showing the use of accessory muscles of breathing with tracheal tug and chest wall recession will reflect the increased effort of breathing common to upper and lower airway obstructed breathing. A vote on the best audio/video could be taken at the end of this section and the source shared with other group members.

2. Working in groups of 2-3, design a one-page parent information sheet on croup which you will use to present to the tutor (playing the role of the parent) using terms appropriate for a lay person to understand.

a. Student-content, student-student, and student-teacher derived. This enables the student, working collaboratively with peers, an opportunity to improve real-world communication skills by translating medical information into layperson's language.

b. It could be assisted by looking online for hospital-designed parent information sheets [e.g., The Sydney Children's Hospital Network: https://www.schn.health.nsw.gov.au/fact-sheets/croup]. Each member of the group could be responsible for part of the information sheet [e.g., description of the condition; symptoms and signs of severity; treatment and recovery timeframe].

3. Working in groups of 2-3, develop an evidence-based management plan for the treatment of croup based upon levels of severity[mild, moderate, and severe] which will be presented by one of your group to the tutor.

a. Student-content, student-student, and student-teacher derived. Again working collaboratively, the student will be able to synthesize theoretical knowledge of physiology, anatomy, and pharmacology with the consequences of infection in a young child and be able to present this succinctly to a colleague.

b. It could be facilitated by reading clinical review articles outlining assessment of croup severity (provided by the tutor) and supplemented by further reading about anatomy, microbiology, pathology, and pharmacology. Examples of croup treatment algorithms in the emergency department will be available in online resources from large hospitals or pediatric societies [e.g., Canadian Pediatric Society: https://www.cps. $\mathrm{ca} / \mathrm{en} /$ documents/position/acute-management-of-croup]. 


\section{Background}

Face-to-face teaching has been the traditional method of medical teaching in the university-centered delivery of theory to large groups in lecture theaters, small group tutorials in hospitals, as well as bedside teaching tutorials where educators taught as they were taught [3]. Over the last 30 years, there has been a progressive shift to problem-based learning and teambased learning, albeit in a face-to-face setting, as medical educators developed a better understanding of pedagogy and embraced the concept of active learning $[1,4]$. However, the COVID-19 pandemic forced another major revision to educational delivery: a shift to online learning.

\section{Experience gained in the first 12 months of the COVID-19 pandemic}

The arrival of COVID-19 prompted several rapid changes to teaching delivery [5]. To facilitate shared approaches among medical schools, the Association of American Medical Colleges resurrected its "iCollaborative" site to serve as a repository for open-access curricular innovations. Over the course of the first 12 months of the pandemic, medical educators submitted $>200$ innovations [https://icollaborative.aamc. org/collection/covid19-alternative-learning-experiences/]. Medical educators addressed clinical and procedural skills through e-learning with the use of open-access didactics, podcasts, reflective activities, distance simulation, and even clinical rotations. Topics were diverse and included those specific to COVID-19 as well as others such as dermatological, radiological, and surgical areas.

Virtual didactic sessions were the earliest e-learning methods incorporated within educational programs using platforms (e.g., Zoom ${ }^{\mathrm{TM}}$, Microsoft Teams ${ }^{\mathrm{TM}}$, Collaborate Ultra $^{\mathrm{TM}}$, Webex ${ }^{\mathrm{TM}}$, etc.) which enabled educators the opportunity to provide lecture-based content and sometimes smallgroup learning methods to a virtual audience. When teaching virtually, further creativity allowed educators to incorporate audience-response technology (e.g., polls, online gaming programs, etc.), small group discussion "breakout rooms," and independent learning [6]. Such approaches were then taken a step further with more innovative approaches such as the open-access "megaflip" [7]. This technique is a large-scale version of a "flipped classroom," a method for teaching that devotes in-class time to application of knowledge acquired outside of the classroom, through independent pre-class study. In the "megaflip," learners reviewed video content prior to a virtual session and applied that learning in both large and small group learning techniques [7]. This could be easily utilized for viewing educational videos of common clinical conditions like croup, bronchiolitis, and asthma which incorporate presenting features, pathology, diagnosis, and management [e.g., search YouTube ${ }^{\mathrm{TM}}$ for videos made freely available with a creative commons license (i.e., copyright free): https://www.youtube.com/watch?v=b7UZELEunow.]

New programs began to integrate virtual simulation opportunities for learners, including for pediatricians in primary care where they were able to focus on team-based skills as they virtually evaluated simulated children presenting in a critical condition [8]. Further, educators have provided a degree of "in-person" clinical training and assessment through the use of telehealth and remote objective structured clinical examinations [9].

Some notable advantages with virtual learning have included increased attendance due to improved accessibility and elimination of travel times, equity in teaching across multiple sites, and facilitation of peer-teaching via virtual chat [10]. Using virtual platforms largely reduced any concerns over volume of learners. With the elimination of travel expenses, virtual learning allowed for "visiting professorships," guest speakers, etc. without any associated cost.

There were also some limitations including so-called "Zoom fatigue" in response to the heavy volume of teaching sessions that occur over such platforms. Content such as bedside teaching can be more challenging to deliver in a virtual setting due to issues associated with noise regulation and the mobility of cameras affecting patient privacy, which is especially concerning in pediatrics. Also, virtual platforms may periodically suffer from technology issues (i.e., poor connectivity), particularly in hospitals, so are limited in their ability to reduce social isolation $[5,11]$.

\section{What is best practice and how is it practiced?}

Rather than merely conveying content such as didactic livestreamed or recorded lectures, online learning can enable flexible, engaging, learner-focused, interactive learning [12]. Online learning materials can be self-directed or incorporate collaboration and communication, where learners manipulate information and develop critical thinking while sharing their knowledge with others [13]. For example, student groups can appraise a journal article in their virtual platform's breakout or chat rooms and then find another article online on the same topic to appraise and compare/contrast, before presenting their findings to the whole group.

As the pandemic recedes and medical education returns to some degree of in-person teaching, educators can consider using online learning on its own or in conjunction with face-to-face teaching through blended learning. By moving some learning activities online, educators can use blended learning to increase the time available during face-to-face teaching for practices that are difficult to undertake online, such as hands-on activities (e.g., physical examination techniques, practical skills in pediatric life 
support)[14], discussions to develop higher-order thinking, role-play, and reflection [15]. Through online learning, learners can review, consolidate, and extend knowledge gained in face-to-face sessions (e.g., completing online practice activities with automated feedback, explanations, and links to additional information) [16].

Taking a flipped classroom approach, learners can use online materials to learn foundational knowledge (usually through pre-recorded short lectures and quizzes) to prepare for face-to-face sessions. In these sessions, teachers can then build on learners' baseline knowledge through hands-on or discursive activities, involving spontaneous feedback and application to clinical practice (e.g., collaboratively working through a patient case in a clinical reasoning format, from patient presentation through to diagnosis and management) [17]. Alternatively, the flipped classroom approach can work well in an online-only format, where students use online learning materials to prepare for online interactive sessions that are based on clinical scenarios, involving large- and/or small-group activities. Unlike didactic lectures, the flipped classroom enables teachers to gauge learners' understanding, provide feedback, and adjust their teaching during the lesson and in future lessons.

Medical educators can apply principles for effective online learning design, which have been explored in medical education and education more broadly and are synthesized in Text Box 3. These principles can be applied to a range of virtual platforms and educational technologies. If using online or blended learning, medical educators can consider all the ways they teach (e.g., online, face-to-face large-group teaching, bedside tutorials, etc.), the way they fit together, and student activity involved in each, with the aim of ensuring that collectively they lead to effective learning [13]. If revisions are needed (as they often are), educators can then (re-)design online or blended learning tasks based on their specific learners, context, content, learning outcomes, learning spaces, and affordances of available educational technologies (e.g., when moving from a lecture-based to a flipped classroom, educators can map out these factors and design online and face-toface learning tasks and learning environments that generate student activity to enhance learning) [13]. Such educational design takes time and is most effective when medical educators have the opportunity for discussion and collaboration with others in multidisciplinary teams, including subject matter experts, educational designers, audio-visual technicians, and librarians [12]. Apart from harnessing the expertise of different professionals, this can lighten the load and lessen the time to create online learning materials. It can help to pay, for example, content writers (who may be junior staff), if small amounts of funding are available.
Text Box 3

Box 3 Proven, effective online learning principles that improve learning (adapted from Scott et al., 2017 [12])

1. Activate learners' prior knowledge before learning and provide opportunities for periodic revision. This could be achieved by beginning each topic with a self-directed quiz (with automated feedback). Learners can use this to revise prior knowledge and clarify what the assumed knowledge is (e.g., learners match a list of symptoms with a corresponding list of diseases). Then provide a quiz at the end of the topic so learners can test themselves on the key points; additional self-directed quizzes for revision can be provided for learners to use at their discretion throughout the course.

2. Divide courses into a series of small sections, each of which learners can focus on and complete in an individual session. This could be achieved by dividing long pieces of course content into small "chunks." Each of these could be recorded as a short lecture (e.g., 10-15 min) or short segment of text of similar reading time. Learners could be instructed to review these segments on their schedule to allow for maximal engagement and retention of materials. A self-directed quiz on key points of each section could be included (see \#1).

3 . Integrate content with self-directed practice activities with automated answers, detailed explanations, and, where relevant, links to further information. This engages learners and increases awareness about, and knowledge of, the key topics. It also involves the testing effect, in which testing learners on recently studied content improves long-term retention. This could be achieved by developing at least one self-directed online quiz (with automated feedback) on each topic. For example, after students learn content on asthma management, they can apply their knowledge to a series of online multiple-choice questions about different patient cases, for which they select the asthma severity and required preventer/reliever medication, means of delivery, and dose. They could also order the steps involved in putting together, preparing, and using a puffer and spacer, for example.

4. Integrate case-based or project-based learning to enable health professional learners to apply new knowledge to clinical questions. This could be achieved by providing an online patient case presentation and leading learners through it as an unfolding case scenario, consisting of a series of trigger questions and model responses that encourage learners to use their clinical reasoning skills to reach a definitive diagnosis and management plan. For example, start an online case by providing patient details (e.g., 5-year-old presents with fever), and ask learners what the differential diagnoses are; then (after thinking through their response) learners click through to the next screen where the differential diagnoses are listed, and then ask learners what they need to ask the child and parents on history-taking; then learners click through to the next screen where the background history is annotated and so on through physical examination, investigations, diagnosis, and management.

5. Include a skills component, either online or face-to-face, if learners need to develop practical, procedural, or communication skills, change in behavior, or transfer of knowledge/skills to health practice. This could be achieved by, for example, learners watching online short lecture recordings on congenital cardiac anomalies as pre-class study. Then in face-to-face or online small groups, students work through online unfolding patient case scenarios (see \#4) while using virtual imaging, cadaveric samples, and/or 3D-printed hearts of congenital cardiac anomalies on which they can identify the relevant anatomy and, eventually, a definitive diagnosis.

6. Enable learners to interact with other learners to seek or share knowledge. Interpersonal interaction is important for learners, especially those learning fully online. However, learners may need carefully structured collaborative activities to motivate them to engage. This could be achieved by, for example, facilitator-led group work in 
virtual break-out rooms, where learners use conference abstract guidelines to peer-review each other's draft conference abstracts and provide constructive feedback. Interactivity during interactive webinars could be achieved by engaging students using online polling entailing closed-item or free-text responses (via built-in features on virtual platforms like Zoom ${ }^{\mathrm{TM}}$ or integrating technologies such as Sli.do ${ }^{\mathrm{TM}}$ ), directing questions to particular groups of learners (e.g., those at specific sites), and inviting students to reply via the virtual platform's chat facility rather than orally if they prefer.

7. Where available, consider using adaptive learning, in which technology adjusts to each learner's needs and performance as they move through an activity. This is dependent on available technology. Where available, it could be achieved by mapping out an online activity so each answer option for each question indicates a learner's level of knowledge. Then, after a learner answers each question, they pass to content and quiz questions that are appropriate for their level of knowledge, which may include viewing/reading additional content and undertaking additional practice questions or skipping content about which the student has demonstrated mastery. In this way, every learner passes along a different trajectory for the activity (a bit like "Choose your own adventure").

8. Avoid high levels of interactivity that do not result in higher knowledge gains. This could be achieved by ensuring that learners' online interactivity is purposeful. For example, in online quizzes such as those suggested in \#3, learners only click on components of quizzes that are required to complete them, including answer options and "submit" buttons. Conversely, purposeful use of interactivity doesn't require learners to click on a series of dot points to reveal the content for each.

When designing multimedia, such as PowerPoint presentations on virtual platforms, educators can consider proven instructional design principles. As shown in Text Box 4, these aim to improve learning by enhancing cognitive processing and reducing cognitive load [18]. Educators should also plan to evaluate their online learning to guide redevelopment. Evaluation should focus on learning outcomes, long-term retention of knowledge and skills, and application to practice, not just learner satisfaction, confidence, and self-assessment of learning or intention to change practice [19]. Regularly evaluating and improving online learning will ensure its sustainability.

Text Box 4

Box 4 Instructional design principles for teaching using multimedia (adapted from Mayer, 2010 [18])

Represent essential material in working memory:

- Teach key concepts before students work with aggregated concepts (pre-training principle)

- Break lessons into learner-controlled chunks (segmenting principle)

- Present words in spoken format (modality principle)

Make sense of material:

- Present words and pictures rather than just words (multimedia principle)

- Present in a conversational or polite style rather than a formal style (personalization principle)

- Use a human rather than a machine voice (voice principle)

Reduce extraneous processing of material without an instructional objective:

- Delete extraneous information (coherence principle)

- Highlight key information (signalling principle)

- Place printed words near related images (contiguity principle)

\section{What is the future of online learning?}

Through emergency remote online learning, learners and teachers have realized its benefits for increasing accessibility and flexibility, not to mention continuity, of learning. Yet, online learning is not an effective design for all forms of medical education in the long term [20]. Indeed, there are essential aspects of medical education that are most effectively learned face-to-face, most notably physical examination techniques at the bedside, such as differentiating stridor from wheeze in a child with croup, auscultation of the chest for bronchial breathing in pneumonia, measuring blood pressure manually with a sphygmomanometer, identifying systolic and diastolic heart murmurs in the four areas of cardiac auscultation, and percussing the abdomen for shifting dullness in patients with ascites.

This is medical educators' TINA (there is no alternative) moment. Now is the time for medical educators to re-imagine learning and teaching and to examine the place of online learning in their courses relative to face-to-face teaching to ensure they make the most effective use of both. Educators can take this opportunity to review the educational design of their online learning program and materials and explore the potential of emerging technologies and teaching practices [21].

\section{Will the clinicians of tomorrow be better prepared or not for the COVID-induced changes in teaching?}

Though there was already a trend to create curricula to train learners in providing effective patient care using telehealth, the COVID-19 pandemic has accelerated implementation at an exponential level. Since the onset of the pandemic, most medical school programs around the world have implemented some degree of telehealth curricula. Virtual OSCEs are likely in the future as well to ensure that students have met the competencies required for successful telehealth practice [5].

In addition to preparation for telehealth, physicians-intraining will be equipped with a multi-modal set of learning methods outside of telehealth. As such, we anticipate they will become more adept at small- and large-group learning in a virtual environment. If we consider Text Box 1, we can envision a scenario in which learners could use virtual platforms to teach one another the presentation and treatment of croup or to create educational materials for parents and families [5].

\section{Conclusion}

It is too early to measure the impact of the pandemic on outcomes related to medical knowledge, skills, and attitudes. The change that it has triggered in medical education has built 
upon existing innovations in the use of educational technology for fully online and blended learning. In the very near future, it will be imperative to describe how learners transitioned to their roles as interns, residents, fellows, and supervising clinicians after emerging from the pandemic. Online learning is thus both the present and future of medical education, and the current generation of physicians-in-training will be the best prepared of any generation to deal with this new modeling their continuing professional development and healthcare delivery. Lessons learned from these experiences may indeed shape the future of medical education.

\section{Availability of data and material N/A}

\section{Code availability N/A}

Authors' contributions DF contributed equally to the idea, review of the literature, writing and editing of the manuscript.

KS contributed equally to the idea, review of the literature, writing and editing of the manuscript.

MR contributed equally to the idea, review of the literature, writing and editing of the manuscript.

\section{Declarations}

Ethics approval N/A

Consent to participate N/A

Consent for publication All three authors consent to the publication of the manuscript.

Competing interests The authors declare no competing interests.

\section{References}

1. McCoy L, Pettit RK, Kellar C, Morgan C (2018) Tracking active learning in the medical school curriculum: a learning-centered approach. J Med Educ Curric Dev 21:5. https://doi.org/10.1177/ 2382120518765135

2. Shelton PG, Corral I, Kyle B (2017) Advancements in undergraduate medical education: meeting the challenges of an evolving world of education, healthcare, and technology. Psychiatry Q 88(2):225-234. https://doi.org/10.1007/s11126-016-9471-x

3. Hodges C, Moore S, Lockee B, Trust T, Bond A The difference between emergency remote teaching and on line learning. (2020). Educause Review. Accessed 3rd March 2021. https://er.educause. edu/articles/2020/3/the-difference-between-emergency-remoteteaching-and-online-learning

4. Graffam B (2007) Active learning in medical education: strategies for beginning implementation. Medical teacher 29(1):38-42. https://doi.org/10.1080/01421590601176398

5. Wijesooriya NR, Mishra V, Brand PL, Rubin BK (2020) COVID19 and telehealth, education, and research adaptations. Paediatr Respir Rev. https://doi.org/10.1016/j.prrv.2020.06.009
6. Cavanagh M (2011) Students' experiences of active engagement through cooperative learning activities in lectures. Act Learn High Educ 12(1):23-33. https://doi.org/10.1177/1469787410387724

7. Beer L, Gray M, Carbajal MM, French H, Vasquez M, Bauserman M, Bonachea EM (2020) Megaflip," a novel approach to National Collaboration for Flipped Classroom Education. Acad Pediatr 20(6):758-759. https://doi.org/10.1016/j.acap.2020.05.027

8. Huang E, Pulice C, Sullivan A (2020) Primary care mock codes during a pandemic: interprofessional team-based emergency education while maintaining social distance. Academic Pediatrics, Volume 20(6):759-760. https://doi.org/10.1016/j.acap.2020.05. 021

9. Coe TM, Jogerst KM, Sell NM, Cassidy DJ, Eurboonyanun C, Gee D, Phitayakorn R, Petrusa E (2020) Practical techniques to adapt surgical resident education to the COVID-19 era. Ann Surg 272(2): e139. https://doi.org/10.1097/SLA.0000000000003993

10. Cobbold C, Wright L (2021) Reflections on practice: a virallyinfected curriculum must adapt or suffer! Focus on Health Professional Education 22(1):1-6

11. Huffman LC, Feldman HM, Hubner LM (2020) Fellows front and center: tele-training and telehealth. Acad Pediatr 20(6):764-765. https://doi.org/10.1016/j.acap.2020.05.023

12. Scott KM, Baur L, Barrett J (2017) Evidence-based principles for using technology-enhanced learning in the continuing professional development of health professionals. J Contin Educ Health Prof 37(1):61-66. https://doi.org/10.1097/CEH.0000000000000146

13. Goodyear P, Retalis S (2010) Technology-enhanced learning. Sense Publishers. https://doi.org/10.1163/9789460910623_002

14. McGarvey K, Scott KM, O'Leary F (2014) 'Round the table teaching': a novel approach to resuscitation education. Clin Teach 11(6): 444-448. https://doi.org/10.1111/tct.12175

15. Nortvig AM, Petersen AK, Balle SH (2018) A literature review of the factors influencing e-learning and blended learning in relation to learning outcome, student satisfaction and engagement. Electronic Journal of E-learning 16(1):46-55 https://www.learntechlib.org/p/ 191054/

16. Scott KM, Morris A, Marais BJ (2018) Medical student use of digital learning resources. Clin Teach 15(1):29-33. https://doi.org/ $10.1111 /$ tct. 12630

17. Lumsden C, Byrne-Davies L, Scott KM Blended learning. In: S. Marshall, Ed., Handbook for Teaching and Learning in Higher Education: Enhancing Academic Practice. Fifth Edition. 2020. London: Taylor and Francis ISBN 9781134109104

18. Mayer RE (2010) Applying the science of learning to medical education. Med Educ 44(6):543-549. https://doi.org/10.1111/j.13652923.2010.03624.x

19. Cook DA, Ellaway RH (2015) Evaluating technology-enhanced learning: a comprehensive framework. Medical Teacher 37(10): 961-970. https://doi.org/10.3109/0142159X.2015.1009024

20. Emanuel EJ (2020) The inevitable reimagining of medical education. Jama. 323(12):1127-1128. https://doi.org/10.1001/jama. 2020.1227

21. Brown M, McCormack M, Reeves J, Brook DC, Grajek S, Alexander B, Bali M, Bulger S, Dark S, Engelbert N, Gannon K 2020 Educause Horizon Report teaching and learning edition. EDUCAUSE; 2020. https://www.learntechlib.org/p/215670/

Publisher's note Springer Nature remains neutral with regard to jurisdictional claims in published maps and institutional affiliations. 